\title{
Corporate Entrepreneurship with Innovation in Mind in one University of Technology in South Africa
}

\author{
Elizabeth Chinomona \\ Vaal University of Technology, South Africa, Faculty of Management Sciences \\ Logistics Department, Vanderbij/park, 1900, South Africa \\ Email: chakubvae@hotmail.com \\ Eugine Maziriri \\ Vaal University of Technology, Faculty of Management Sciences \\ Vanderbijlpark, 1900, South Africa \\ Email: euginemaziriri@yahoo.com \\ K.C.Moloi \\ Vaal University of Technology, Faculty of Human Sciences \\ Vanderbijilpark, 1900, South Africa \\ Email: conniem@vut.ac.za
}

\section{Doi:10.5901/mjss.2014.v5n23p20}

\section{Abstract}

This qualitative study investigates corporate entrepreneurship because the researchers believe that it stimulates innovation and encourages calculated risk taking throughout its operations. The researchers collected qualitative data through semi-structured interviews with document exploitation and observations were used to collect the data from multiple sources in this qualitative study. To be able to develop a logical argument, One University of Technology (UoT) will be discussed first, then concepts like corporate entrepreneurship will first be discussed and this discussion will be followed by an interrogation of innovation, sustainability, efficiency and effectiveness. Managerial implications of the findings are discussed and limitations and future research directions are indicated.

Keywords: University of Technology (UoT), Entrepreneurship, Corporate entrepreneurship, Innovation, Sustainability, Efficiency, Effectiveness.

\section{Introduction}

The one UOT under investigation is a tertiary institution located in Vanderbijpark, South Africa. It is one of the largest residential Universities of technology, with about 17,000 students, 300 programmes, all primarily taught in English (www.out.ac.za). The campus and facilities are conducive to learning, research, recreation and sport, art and culture, and community service (Chinomona, Chinomona \& Moloi 2013). Its academic emphasis is on career-focused diploma and degree programmes that prepare students for the world of work. Many programmes include practical experience in the workplace, so that students "hit the ground running" when they begin their working lives (University of Technology Teaching and Learning Model 2012; Radebe 2013). It has four faculties (Applied and Computer Science, Engineering and Technology, Human Sciences, Management Sciences) and its vision is to be a dynamic centre of technology leading in quality education for the nation (www.out.ac.za).

The vision for the university is "We are a University that leads in innovative knowledge and quality technology education" and the mission statement is "to produce top quality employable graduates who can make an impact to society by adopting cutting edge technology and teaching methods, producing a scholarly environment conducive to learning and innovation and developing a Product Quality Management (PQM) that meet the needs of society in Africa and beyond" (Chinomona et al., 2013).

This study addresses the problem which the university is currently facing, key questions and aims of the study will be identified, literature review will be conducted to have an overview or to gain a depth understanding of the concepts 
entrepreneurship, corporate entrepreneurship, innovation, sustainability, efficiency and effectiveness. The main purpose of this study is to be able to develop or to bring innovation within an existing business through identification of a new opportunity or business idea. By being able to develop any kind of innovation, the institution will be able to enhance sustainability, efficiency and effectiveness.

The university will be able to offer a service that is present at other universities like University of Johannesburg (U.J) and Witswaterand University (Wits). The One UoT is one of 6 Universities of Technology in South Africa. The other Universities of Technology comprise of Cape Peninsula University of Technology (CPUT), Central University of Technology (CUT), Tshwane University of Technology (TUT), Durban University of Technology (DUT), Mangosuthu University of Technology (MUT).

\section{Problem Statement}

According to Chinomona et al., (2013) there are problems with issues of efficiency and effectiveness at the university and a lot is being done to eradicate the problems through policy changes and modifications of the Teaching and Learning Model and Transformation document. Management of campus cafeterias continues to be a challenge for most universities in South Africa and meeting the demands or needs of the University's community, regarding to the food which they eat on campus is a challenge. With the increase in numbers of staff and students, in January 2014 the one UoT introduced a new private food outlet which was licensed to prepare and sell food on campus. According to Ryu, Lee and Kim (2012:200) poor service quality increases customer dissatisfaction and the likelihood that customers will dine at a competitor and become an active companion in persuading others to go elsewhere. In another study it was noted that waiting time, staff attitude, food quality and variety significantly affect customer satisfaction (Agnes, Law-Hui \& Zhao, 2004:545). There is need to have more food outlets for variety and effective reasons.

Some students and staff now prefer to buy food to nearest retail outlets such as Pick n' Pay which is located at Bed-worth shopping Centre in Bed-worth Park, Vanderbijlpark. The institution does not have different food service operations or businesses that are providing many variety food options and delivering fresh, healthy and tasty ingredients in a way that pleases the students. This means additional transportation costs are incurred by the students and their safety is at risk due to the fact that they are now purchasing food in some of the areas where crime is high. The institution is also losing money because of this, having so many food outlets will solve the problem.

Since the main business for the institution is to provide education to its students and having a mission to produce employable graduates who can positively impact in the society they live. It is fundamental for the one UoT to employ the right strategies and resources that will allow them to achieve their ambitious vision which is to be a university that leads in innovation, knowledge and quality technology education (Radebe, 2013). It is of vital importance for the university management to rectify the challenge by taking into consideration the living standards of students which include the food they eat on campus.

Since innovation entails something new or different, the best way to solve the problem would be to establish a campus shopping centre for the one UoT community. The definition of the modern shopping centre refers to a number of enterprises managed as an operating unit (Warrington, 2001). Warnaby, Bennison and Davies (2005) describes the shopping centre as planned retail developments comprising various retail outlets which are under one freehold ownership, managed and marketed as unit.

According to Wee and Tong (2005:3) a shopping centre is defined as a group of retail and other commercial establishments that is planned, developed, owned, and managed as a single property" in accordance with the International Council of Shopping Centres (ICSC), one of the largest and most authoritative organisation on shopping centers in the world. For the purpose of this study the one UoT shopping centre will feature a group of retail shops, stationary stores, restaurants, and other businesses with a common interest of enhancing customers satisfaction by offering a wide variety of products to the students and the employees of the one UOT such as groceries and clothing.

\section{Solutions to the Problems}

At this shopping centre, one UoT will have its own supermarket which will serve as the anchor store of the shopping centre. The one UOT supermarket will be the 'corner shop' where students and staff can get their daily shopping as well as ready-made meals, pre-packed sandwiches, fresh fruit juices and a variety of fresh produce. Berman and Evans (2004) defines a supermarket as a self-service food store with grocery, meat, and produce departments and minimum annual sales of $\$ 2$ million. A supermarket is a self-service store offering a wide variety of food items and household merchandise, organised into departments with a selling area of at least 150m2 (Riungu, 2011). The one UoT supermarket 
at this new shopping centre will be a large retail unit with an extensive assortment (width and depth) of goods and services that are organized into various departments for the purpose of buying, promotions, customer service, and control. This supermarket will be larger in size offering the one UoT Community with a wide range of food-products and house products organized into aisles. For example the supermarket will typically comprises meat, fresh produce, dairy, and baked goods aisles, along with shelf space reserved for canned and packaged goods as well as for various non-food items such as apparel clothing, household cleaners, sporting equipment and pharmacy products. The main focus of this supermarket will be to offer appealing, healthy products that are priced in a favorable way and positioned in the store in a way that makes them easy to see.

The one UoT shopping centre will also have an outlet for a well-known brand franchise answering to the name KFC (Kentucky Fried Chicken) which is a fast food restaurant that specializes in fried chicken. So many students around campus crave the delicious cooked chicken of KFC throughout the day without having the dedication to go into town for it. The perfect solution would therefore be to have a KFC restaurant on campus, it would keep the students happy and business would be booming. KFC has a good reputation and it provides affordable scrumptious meals for its customers. It offers products such as chicken pieces, chips, ice creams, chicken fillet burgers and wraps, as well as salads and side dishes, French fries and coleslaw, desserts and soft drinks. KFC is known for the slogan "finger licking good", which has since been replaced by "Nobody does chicken like KFC" and "So good."

In South Africa KFC It is one of the dominant fast food chain restaurants. KFC was established in South Africa since 1971. Presently KFC is operating over 450 franchised stores throughout South Africa. KFC won franchise of the year in 1990. This is mainly due to the fact that KFC has developed its brand over 33 years and has used franchising to achieve this.

Other facilities to be available at the shopping centre would be a pharmacy, books stores, stationery stores, beer hall, banks, a souvenir counter, a coffee shop, snack shop, a hair salon and a driving school, to enable students have their driving lessons on campus. All these outlets will be available on campus at the one UoT shopping centre in order to provide the one UoT community all the day to day essentials to live comfortably without having to go off campus.

For the past two years one UOT permitted a private driving school (Solly's Skills Driving Academy) to operate on one UoT property. This means that all revenue generated go directly to the outsourced driving school, instead of growing one UoT's profits. One UoT should strongly consider the possibility of establishing its own driving school under innovation and corporate entrepreneurship. One UoT can consider the possibility of creating their own driving academy. They have an excellent faculty of Applied and Computer Sciences, who can collaborate and write their own computer simulated driving programme. Driving simulation software and hardware already exist on the market and was introduced in July 2012 in South Africa by Coega, to universities and colleges in the Eastern Cape region. The simulators imitate real vehicle parts, which include a right hand driver's unit, seat belt, earphones, steering wheel, indicator, windscreen wiper controls and five-speed manual gearbox. This gives the learner a realistic experience. Being able to drive and have a valid license in today's job market is essential (WSU: 2012).

If one UoT implements the driving simulation programme or create their own, it will lead to huge profits. This will not overtake the License Department's function or role, as students still have to write their learners license and driving test at the licensing department.

\section{Aims of the Activity}

$>$ To be able to identify the current problem in the organisation that needs to be rectified.

$>$ To be able to venture into corporate entrepreneurship with innovation in mind

$>$ To determine if the inextricable link between corporate entrepreneurship and innovation can enhance sustainability, efficiency and effectiveness

$>$ To be able to come up with an innovative entrepreneurship idea that will be able to solve the problem which the organisation is currently facing.

\subsection{Research questions}

This study poses the following research questions:

$>$ What impact does corporate entrepreneurship have on the one UoT?

$>$ What impact does innovation have on the one UoT?

> How does innovation lead to sustainability, efficiency and effectiveness at the one UoT? 
$>$ What are the strengths of the one UoT?

\section{Literature Review}

This study is going to review literature on entrepreneurship, corporate entrepreneurship, innovation, sustainability, effectiveness and efficiency.

\subsection{Entrepreneurship}

The term entrepreneurship has a history that dates back to 1732, when the Irish economist Richard Cantillon used the word in reference to individuals with "a willingness to carry out forms of arbitrage involving the financial risk of a new venture" (Minniti \& Lévesque, 2008:603). According to Aardt, Hewitt, Bendeman, Bezuidenout, Rensburg, Aardrt, Van Der Bank and Visser (2011:04) entrepreneurship is defined as the act of initiating, creating, building, expanding and sustaining a venture, building an entrepreneurial team, and gathering the necessary resources to exploit an opportunity in the marketplace for long-term wealth and capital gain.

Entrepreneurship encompasses acts of organisational creation, renewal, or innovation that occur within or outside an existing organisation (Sharma \& Chrisman, 1999:17). In addition, Hisrich (2005:02) defined entrepreneurship as the process of creating something new with value by devoting the necessary time and effort, assuming the accompanying financial, psychic, social risks, and receiving the resulting rewards of monetary, personal satisfaction and independence. From the definitions given it is possible to conclude and appreciate that entrepreneurship is the process whereby an individual or individuals start or develop a new venture or business unit and this can include an entrepreneurial individual acquiring a franchise or an existing business or firm.

\subsection{Corporate entrepreneurship}

According to Zahra, Filatotchev and Wright (2009:248) corporate entrepreneurship refers to the activities a firm undertakes to stimulate innovation and encourage calculated risk taking throughout its operations. These activities reinforce the company's position in existing markets while allowing it to enter new and perhaps more lucrative growth fields. Corporate entrepreneurship is the process whereby an individual or a group of individuals, in association with an existing organisation, create a new organisation or instigate renewal or innovation within that organisation (Sharma \& Chrisman, 1999:17). Aardt et al., (2011:366) believe that corporate entrepreneurship is a term that is used to describe entrepreneurial activity within an existing business. In general, corporate entrepreneurship is seen as an effort of promoting innovation from the internal organisational perspective. Similarly, Strydom (2008:316) defines corporate entrepreneurship as entrepreneurship that occurs in an existing business. From the authors definitions of corporate entrepreneurship it can be concluded that corporate entrepreneurship is the process when a person or a team develops a new business unit within an existing business through identification of a new opportunity or business idea.

\subsection{Innovation}

Various definitions have been developed to explain what innovation is all about. According to Barthwal (2007:247) the word "innovation" itself originates from the Latin word "innovare", which can be translated as "renewal". To be innovative thereby indicates the ability to create something new (Barthwal, 2007:247). Innovation plays a very important role in any form of organisation. Naylor (1999:212) describes innovations as ideas that are developed into new products or processes and they result in changes that customers recognize as new. Similarly, Dess (2007:96) describes innovation as using new innovation to transform organisational processes or create commercially viable products and services. In simpler terms, innovation is the process of making improvements by introducing something new. Additionally, it is the introduction of something new or different and it can be identified as a process of bringing the best ideas into reality, which triggers a creative idea, which generates a series of innovative events.

It is crystal clear that Innovation and corporate entrepreneurship are closely related. The subject of corporate entrepreneurship is important in this study, because any factor that affects corporate entrepreneurship should, to a larger extend also affect innovation. This is because by definition, innovation is a component of corporate entrepreneurship and without innovation, they is no corporate entrepreneurship. 


\subsection{Sustainability}

Sustainability has become a buzz word for entrepreneurs, scholars, policy makers, and business organisations. Crane and Matten (2007:23) provided a more specific definition, referring to sustainability as the long-term maintenance of systems according to environmental, economic and social considerations. In the environmental perspective the basic principles of sustainability focus on the effective management of physical resources and require addressing problems such as the depletion of non-renewable resources, the effect of industrialization on biodiversity and the production of pollution (Crane \& Matten, 2007:23).

In the field of business, Landrum and Edwards (2009:4) define a sustainable business as one that operates in the interest of all current and future stakeholders in a manner that ensures the long-term health and survival of the business and it's associated with economic, social, and environmental systems. Sustainability is a business strategy that drives long-term corporate growth and profitability by mandating the inclusion of environmental and social issues in the business model (Evans \& Smith, 2002:76). From the authors definitions it can be seen that sustainability is a process by which companies manage their financial, social and environmental risks, obligations and opportunities.

\subsection{Efficiency and effectiveness}

Efficiency and effectiveness are central terms used in assessing and measuring the performance of organisations. According to Zheng (2010:763) effectiveness oriented companies are concerned with output, sales, quality, creation of value added, innovation, and cost reduction. It measures the degree to which a business achieves its goals or the way outputs interact with the economic and social environment. Usually effectiveness determines the policy objectives of the organisation or the degree to which an organisation realizes its own goals (Zheng, 2010:763). Meyer and Herscovitch (2001:299) analyzed organisational effectiveness through organisational commitment.

According to Heilman and Kennedy (2011:29) effectiveness helps organisations to assess the progress towards mission fulfillment and goal achievement. To improve organisational effectiveness management should strive for better communication, interaction, leadership, direction, adaptability and positive environment. Efficiency measures relationship between inputs and outputs or how successfully the inputs have been transformed into outputs (Low, 2000:252). According to Pinprayong and Siengthai (2012:29) business efficiency reveals the performance of input and output ratio, while organisational efficiency reflects the improvement of internal processes of the organisation, such as organisational structure, culture and community. Excellent organisational efficiency could improve entities performance in terms of management, productivity, quality and profitability. From the authors' definitions it can be concluded that effectiveness is the capability of producing a desired result while efficiency is generally the extent to which time, effort or cost is well used for the intended task or purpose.

Since corporate entrepreneurship entails the act of initiating new ventures or creating value with an already established organisation, by establishing a new shopping centre the one UoT would have succeeded in developing a new business unit (shopping centre) within an existing business (providing education). According to Zakim (2000:37) job creation is the provision of new opportunities for paid employment, especially for those who are unemployed. Since unemployment is a pervasive problem in South Africa, this new venture will also positively contribute in the creation of jobs because the shopping centre will need to be constructed and after that staff members to run it. The retail business management students who have got modules for shopping centre management and the hospitality management students of the one UoT will also have the opportunity to work at the shopping centre applying their knowledge and skills by practically doing their work in order to satisfy the students and staff of the one UoT.

Having a shopping centre on campus will be the best innovative idea that will solve one UoT's challenge of not having perfect food service providers. The shopping centre will be a fantastic place for students who want all their favorite shops under one roof. According to Sari, Kusuma and Tedjo (2011) university students are consumers of shopping malls within the age range of $18-25$. Studies also show that this segment of consumers is highly conspicuous in their shopping. Conspicuous shopping can be defined as the competitive and extravagant practices and leisure activities that aim to indicate membership to a superior social class (Patsiaouras \& Fitchelt, 2012). Young people want to be seen with trending items or products in the market, for example at a shopping centre or mall. Most students will view the one UoT shopping centre as an interesting place or a form of entrainment while others will perceive shopping at the centre as a way of having fun and socializing with class mates or friends.

In order to improve the weakness of having a poor service campus cafeteria, the one UoT can also introduce a KFC franchise which will be located at the newly established shopping centre. Gordon (2006) defines a franchise as system in which a licensor grants a license to franchisees to use the trade name and an entire or part of a business 
format. The Franchise Association of South Africa (2006) defines a franchise as a grant by the franchisor to the franchisee, entitling the latter to use of a complete business package containing all the elements necessary to establish a previously untrained person in a franchised business and enable him or her to run it on an ongoing basis, according to guidelines supplied, efficiently and profitability. A good example in this context will be the one UoT being the franchisee whereas KFC will be the franchisor. Therefore it will be of vital importance for the one UoT to enter into a franchise contract with KFC

After the one UoT has entered into a franchise contract with KFC it will be able to gain the following:

$>$ Ongoing advice, training, research and development. The franchisor (KFC) will provide knowledge and business expertise, and will gain continuous support in the running of the business throughout the duration of the business relationship of KFC and one UoT.

> Brand awareness - The one UoT will be supported in marketing the brand to the one UoT community. One UoT will be in association with a well-established KFC brand and product. Operating under the banner of a KFC franchise allows a franchisee one (UoT) to take advantage of the previously established brand of the business.

$>$ Infrastructure- the one UOT will also enjoy the benefits of service infrastructure such as central marketing.

$>$ Increased success rate- Aardt et al., (2011:366) states that franchisees have a much better chances of business success than franchisees that start up their own business. The reason is that management and training systems are in place to enhance effectiveness and efficiency, which in turn reduces the risks of failure. This clearly shows that by introducing a franchise on the one UoT campus the chances of failure are limited.

$>$ The one UoT will receive assistance with outlet design and equipment purchasing.

$>$ The one UoT will receive initial management training and continuing management assistance.

$>$ The one UOT will receive access to established standard procedures, operating manuals and stock control systems.

KFC is has got a well-known brand which is known by a lot of customers. This can be an advantage to the franchisee one (UOT) because a lot of students and staff know about KFC. According to Green (1994:39) college students have a tendency to desire brand name restaurant food. The most important factors consumers consider when choosing a restaurant ranking is food quality, service, value, and cleanliness whether their food is prepared the way they desire it or prepared according to the food service quality standard. When customers choose food based on a brand name, the gap is reduced between the customer's expectation of food and the actual food delivered. Also, branded name product foods are preferred because of the reputation of the manufacture related to appearance, quality, fresh ingredients, familiarity, price, and value (Green, 1994:40). Some can argue that one UoT has no space to venture into all the above mentioned businesses but as what can be seen one UoT has a lot of land which is underutilized which can be used efficiently and effectively.

\section{6. $\quad$ Findings from the Literature}

From the literature definitions of key terms such as entrepreneurship, corporate entrepreneurship, sustainability, efficiency and effectiveness were stated and explained. This gave a broad understanding or a theoretical comprehension of the key terms related to the topic.

The main finding from the literature is that it can be determined that innovation can give an organisation the competitive advantage it needs to be a success in the market. An organisation like one UoT can venture into corporate entrepreneurship where it can engage itself in entrepreneurial activity within its existing business which is providing education (UoT Teaching \& Learning Model 2012; Radebe 2013; Chinomona et al., 2013) One way of doing this is by having newly shopping precinct in the University which will provides the day to day essentials to live comfortably without having to go off campus. This will lead to sustainability, effectiveness, and efficiency at the one UoT.

\section{Methodology}

In this study a qualitative approach is used rather than quantitative because information obtained though subjective is believed to be soft, rich and deep because there is room for probing the subjects' interests (Wilson 2010; Cooper \& Schindler 2011). However results obtained from qualitative are more descriptive but are difficult to quantify and prone to measurement error and bias (Hair, Babin, Anderson \& Tatham 2010). In qualitative the researcher builds a complex, holistic picture, analyse words, reports detailed views of informants and conducts the study in a natural setting. Cresswell (1994) divides qualitative research into five main qualitative research types which are the biograghy, phenomenology, 
grounded theory, ethnography and case study.

A single case study design approach of one UoT is utilized in the current research to analyse the effects of corporate entrepreneurship. A case study is an empirical enquiry that investigates a contemporary phenomenon within its real-life context, especially when the boundaries between phenomenon and context are not clearly evident and it relies on multiple sources of evidence (Yin, 1994). According to Cavaye (1996), a case study research investigates predefined phenomena and does not involve explicit control or manipulation of variables but rather the focus is on in-depth understanding of a phenomenon and its context. Typically, case studies combine data collection techniques such as interviews, observation, document and text analysis (Darke, Shanks \& Broadbent, 1998). As elaborated earlier qualitative data collection and analysis methods (which are concerned with words and meanings) have been used in this study.

A single case approach has been an increasingly popular methodology and it has enabled various authors to provide some very important new insights into the subject area (Clarke \& Rimmer, 1997; Wrigley, 2000). Owing to the limitations of relying on one source of information (UoT) when collecting data on this case, the study adopted data triangulation approach. Data triangulation refers to the use of multiple sources of data. Multiple and independent sources of evidence, including observations, interviews and document exploitation such as use of one UoT transformation documents has been used (Yin, 1994). In this study observations and document exploitation were used to corroborate the interview data and, by so doing, developed convergent lines of inquiry.

\subsection{Focus group}

The study conducted a focus group of 5 one UoT post graduate students and 10 undergraduate students' separately. A focus group is a form of quantitative research in which a group of people are asked questions about their opinions, perceptions, beliefs and attitudes towards a product, service, concept or idea (Bradley, 2007; Wilson, 2010). Bryman (2004) and Cooper and Schindler (2011) defined a focus group as an interview conducted by a trained interviewer among a small group of respondents. Questions are asked in an interactive group setting where participants are free to give views from any aspect and talk with each other. Focus group allows interviewers to study people in a more natural conversation pattern than typically occurs in a one to one interview. Fairly low cost compared to surveys, as one gets results relatively quickly and increase the sample size of a report by talking to several people at once. However there is the disadvantage of observer dependency raising questions of validity unless the interviewing of the focus group is repeated several times (Zikmund, Babin, Carr \& Griffin, 2010).

\subsection{Individual interviews}

Individual interviews were also conducted concerning corporate entrepreneurship at OUT. Eleven (11) one UoT lecturers and ten (10) UoT management staff who are UoT authenticated Card holders were interviewed. The respondents were chosen for the purpose of providing inside information about corporate entrepreneurship, efficiency and effectiveness at one UoT. The researcher managed to conduct the interviews while at the same time recording the interviews and taking short notes for future coding. The general observation was that each interview would trigger the necessity for another interview as the themes began to unfold. The convergent in-depth interviewing used in this study allowed the researcher to develop, clarify, verify and refine the core issues of the interview protocol. During the early stages, the content of the interview was unstructured and flexible in order to allow the interviewees to communicate freely their experiences and considered views concerning corporate entrepreneurship. The process used in the interview became more structured as the interviewer converged in specific issues of the research problem and sought further clarifications on certain issues. Finally after conducting a total of thirty (30) interviews the researcher felt it was enough but needed to further corroborate the findings with the data from five more informal conversations. For the purpose of the informal conversations, security staff and general hand workers were chosen in order to reduce biases of the information got. During the informal conversations, field notes were also taken and memos developed thereafter. Unlike in quantitative research, qualitative research views literature review as an ongoing process and serve as a source of data (Goldkuhl \& Cronholm, 2003; Glaser \& Strauss, 1967).

\subsection{Document exploitation}

As put forward by Turner (1983), literature from documented material should be viewed equally the same as field notes. The same point was buttressed by Glacer $(1998,1992)$ who referred to documented literature as "everything is data" and Strauss and Corbin (1990) who asserted that a "cache of archival material" is equivalent to a collection of interviews and 
field notes. In this study the researchers reviewed documents with literature on one UoT policies, Teaching and Learning model for one UoT (2012), UoT transformation document (2013), information posted on UoT official websites. These documents served two purposes. Firstly, they were treated as another source of data collection. Secondly, as noted by Goldkuhl and Cronholm (2003), prior reading provided models to help the researcher make sense of the data gathered on UoT through strategies in the field and probe further the interviewees where necessary.

\subsection{Observation method}

Finally, the researchers had an opportunity to observe one UoT students and lecturers in how and where they purchased their groceries and food. Again memos were developed from the notes taken and used to augment the data collected by means of interviews, informal conversations and documented material. Recommendations, limitations of the study and suggestion of future research direction and conclusion crown up the current study.

\section{Recommendations}

The existing spate of literature proves beyond reasonable doubt that there is need to instill a spirit of corporate entrepreneurship at one UoT. Efficiency and effectiveness are still below required level and the education system is one of the poorest among African countries owing to its apartheid regime (Meyer \& Hofmeyer 1995; Enslin 2001; Soudien 2004). The education given to students is not relevant to its recipient (Bundy 2005). A lot needs to be done to have efficient and effective education which results in global competitiveness, lifelong learning and also corporate entrepreneurship.

Innovation, efficiency and effectiveness are terms that have been defined differently by different authors. There is still need to improve our corporate entrepreneurship thinking in order for it to be of high quality, up to standard and relevant to the one UoT students. Universities alone cannot do the change on their own it requires participatory approach from all angles. This will make the transformation efficient and effective. It results in no criticism from other sectors of society because everyone will have been given room to participate. Though a participatory approach is so laborious and takes too much time it's really necessary to have the transformation in institutions of higher learning (Radebe 2013). No quick fix solutions or borrowed models can rescue higher education in South Africa, it should be original and from within the country. It is important to note that neither political nor academic egoistic monopoly can transform universities, only teamwork and a spirit of togetherness can change the higher education sector (Chinomona et al ., 2013).

At one UoT there is need to come up with new policies and a mindset of transformation for our students to be the cream of the country and internationally. Literature has reviewed that there is far reaching implications for quality competencies and capabilities as well as generic skills that UoT students would have attained on completing their studies to enhance their potential for future employment, contribution to economic growth, poverty eradication, social justice and lifelong learning (Teaching \& Learning Model, 2012). So a lot needs to be done in changing teaching practices and go for corporate entrepreneurship.

To sum up, as shown above, this study has looked at the five key words which are one UoT, efficiency, effectiveness, corporate entrepreneurship and innovation. Many authors have tried to define these most important concepts differently. For positive change to be realized around these five aspects there is need for all stakeholders to come together have an input such that all the views will be included. Greatest challenge facing higher education institutions worldwide is the need to improve corporate entrepreneurship. The quality of learning and teaching for its students and also the shift from teacher centred approach to a more learner centred approach, this involves putting the learner's needs at the core of activities (Chinomona et al., 2013). It is also important to note that students are not empty vessels they are very brilliant some of them. They should be allowed to make their own decisions and learn on their own concerning corporate entrepreneurship.

\subsection{Implications of the study}

The ever-increasing importance of corporate entrepreneurship, effectiveness, efficiency and innovation in South African high educational institutions (UoT) for viability reasons cannot be overlooked. High quality of education and also high standards and relevance of education can lead to institutions of higher learning have quality graduates who can be employable everywhere and have a sustainable advantage everywhere. The current study is an attempt to undertake a research in an often most neglected context (UoT) but yet an important sector of the South African higher institution of learning. Therefore, the findings of this empirical study are expected to have to provide fruitful implications to both 
practitioners and academicians.

On the academic side, this study makes a significant contribution to the organisational behaviour literature by systematically exploring the impact of corporate entrepreneurship, efficiency and effectiveness in the context of university staff members and students. On the practitioners' side, communications across the all stakeholders in South Africa's tertiary institutions are highlighted. All people need to be involved in decision making including the parents for efficacy to be realised. This study therefore submits that educational leadership that formulates policies that lead to high quality education makes institutions of higher learning enjoyable places to work for and for students to enjoy learning.

One UoT top management will learn and change for the better in the way they are doing their things and focus more on corporate entrepreneurship as it brings more money to the institution, student learning and research. Staff development programmes are run at this university to train lecturers to be of high quality but a lot is needed in providing adequate resources for this dream on corporate entrepreneurship to be realised.

\subsection{Limitations and Future research}

In spite of the contribution of this study, it has its limitations which provide avenues for future researches. First and most significantly, the present research is conducted from the staff member and students' perspective UoT University in South Africa. Perhaps if data collection is expanded to include other tertiary institutions employees and students, the research findings might be more insightful. Future studies should therefore consider this recommended research direction. This study also excluded top management employees and future research can also try and interview the top management which includes the Vice Chancellor and her deputies. There is also the problem of common method bias. Qualitative was purely used in this study. It was going to be more robust if the study included both qualitative and quantitative methods.

All in all, these suggested future avenues of study stand to immensely contribute new knowledge to the existing body of corporate entrepreneurship literature, a context that happen to be less researched by some researchers in Africa.

\section{Conclusion}

In this study the key words has been well introduced, key questions and aims of the study have been identified, a literature review has been conducted to have an overview or to gain a depth understanding of the concepts UoT, entrepreneurship, corporate entrepreneurship, innovation, sustainability, efficiency and effectiveness. In this assignment it is crystal clear that for one UoT to improve its performance it can implement an innovative entrepreneurial business idea of venturing in into corporative entrepreneurship by introducing a new shopping centre on campus, driving school and a beer hall such that students do not seek these services outside. If one UoT fails to implement this innovative idea they run the risk of losing ground to competitors, losing students, losing key staff, or simply operating inefficiently. Innovation is imperative because it allows the organisation to adapt to change, to increase market share, to meet the buyers' standards or requirements and lastly to improve productivity or reduce production costs.

\section{References}

Aardt, V., Hewitt, M., Bendeman, H., Bezuidenhout, S., Rensburg. J.V., Aardt, C., Van der bank, J., and Visser, T. (2011). Entrepreneurship \& New Venture Management. $4^{\text {th }}$ Edition. Cape Town: Oxford University Press Southern Africa.

Agnes, K.Y., Hui, Y.V. and Zhao, X. (2004). Modelling repurchase frequency and customer satisfaction for fast food outlets. International Journal of quality, 21(1): 545-563.

Barthwal, R.R. (2007). Innovation and Entrepreneurship. 2rd Edition. Chichester, UK: John Wiley \& Sons.

Berman, B. and Evans, J.R. (2004) Retail management: A strategic approach. 9th Edition. New Jersey: Pearson Education.

Bradley, N. (2007). Marketing research tools and techniques. New York:Oxford University Press.

Bryman, A. (2004). Social Research Methods. 2nd ed. Britain:Oxford University Press

Bundy, C. (2005). Global patterns, local options? Some implications for South Africa of international changes in higher edication. Perspectives in Education, 23(2), 85-98.

Caruso, M.L. (2010). Campus Based Snack Food Vending Consumption. A Senior Honors Thesis. United States. The Ohio State University.

Cooper, D.R. \& Schindler P.S. (2011). Business Research methods. 11 th ed. Singapore:McGraw- Hill.

Cresswell, N.K. (1994). Qualitative inquiry and research design: Choosing among five traditions, Thousand Oaks, CA. Sage.

Creswell, J.W. (2003). Research Design. Qualitative, Quantitative and Mixed Methods Approaches. Second Edition. London: Sage Publications.

Denzin, N.K. \& Lincoln Y.S. (1994). Introduction: Entering the field of qualitative research. In N.K.Denzin \& Y.S.Lincoln (Eds). Handbook of qualitative research (page 1-17). Thousand Oaks, CA: Sage. 
Chinomona, E. Chinomona, R. and Moloi, K.C. (2013). Elements of Quality Assurance at Institutions of Higher Education: Vaal University of Technology in South Africa. Mediterranean Journal of Social Sciences. 4 (14): 643-656

Cornuel, E. (2007). Challenges facing business schools in the future. Journal of Management Development. 26 (1):87-92

Crane, A. and Matten, D. (2007). Business Ethics, 2nd Edition. New York: Oxford University Press.

Dess, E.S. (2007). Innovation Management in Business. $3^{\text {rd }}$ Edition. New Jersey: Prentice Hall.

Enslin, P. (2001). Multicultural education,gender and social justice: liberal feminist misgivings. International Journal of Educational Research ,35, 281-292.

Evans, S. and Smith, E.Y. (2002). A sustainable business. $4^{\text {th }}$ Edition. New York: Oxford University Press.

FASA. (2006). FASA's 2007 Franchise Directory. Bruma: Franchise association of Southern Africa (FASA).

Gordon, B. (2006). The standard Bank Franchise Factor. September 2006. Franchise Directions.

Green, C.G. (1994). Nutrition Awareness and Branding in College/University Food Services: What Motives These Trends? Journal of College \& University Food Service, 2(1):39-58.

Hair, J.F., Babin,B.J., Anderson,R.E. \& Tatham, R.L. (2010). Multivariate Data Analysis. A Global Perspective. $7^{\text {th }}$ ed. London: Prenticehall.

Heilman, S., and Kennedy, L. (2011). Making Assessment Easier with the Organizational Effectiveness Model describe a comprehensive, step-by-step, mixed-methods assessment model. American College Personnel Association and Wiley Periodicals, 15 (6):29-32.

Hisrih, R.D. (2005). Entrepreneurship: New Venture creation.5th Edition. New Delhi: Mc Graw Hill.

Landrum, N.E. and Edwards, S. (2009). Sustainable Business: An Executive's Primer, New York: Business Expert Press.

Low, J., (2000). The value creation index. Journal of Intellectual Capital, 1(3): 252- 262.

Meyer, J.P. and Herscovitch, L. (2001). Commitment in the workplace: toward a general model. Human Recourse Management Review. 11(3): 299-326.

Meyer, S \& Hofmeyr, J. (1995). Evaluation Needs In South African Education: A Policy Perspective. Evaluation and Program Planning, 18(4),355-363.

Minnitim, M., and Levesque, M. (2008). Recent developments in the economics of entrepreneurship, Journal of Business Venturing, 23: 603-612.

Naylor, D. (1999). Creativity and Innovation management. 1st Edition. London: New Jersey.

Patsiaouras, G. \& Fitchett, J.A. (2012). The evolution of conspicuous consumption. Journal of historical research in marketing. 4(1):154176.

Pinprayong, B. and Siengtai, S. (2012). Restructuring for organizational efficiency in the banking sector in Thailand: a case study of siam commercial bank. Far East Journal of Psychology and Business. 8(2):29-42.

Radebe, J.N. (2013). Draft: Transformation Policy: Vaal University of Technology.

Riungu, C.K. (2011). Effects of supermarkets on fresh on fresh fruit and vegetables: small-scale farmers in central Kenya. Master of Science Degree in Agricultural and Applied Economics. Kenya: Egerton University

Ryur, K., Lee, H.R. and Kim, W.G., (2012). The influence of the quality of the physical environment, food and service on restaurant image, customer perceived value, customer satisfaction and behavioral intentions. International Journal of Hospitality Management, 24(2): 200-223.

Sarl, A.A., Kusuma, H.E and Tedjo, B. (2011). A strategic planning for a college student- segment Shopping Mall. International research journal of business studies. 4 (2): 157-168

Sharma, P., \& Chrisman, J. J. (1999). Toward a reconciliation of the definitional issues in the field of corporate entrepreneurship. Entrepreneurship Theory and Practice, 23(3): 11-27.

Strydom, J. (2008). Principles of Business Management. 1'st Edition. Cape Town: Oxford University Press Southern Africa.

Soudien, C. (2010). Grasping the nettle? South African higher education and its transformative imperatives. South African Journal of Higher Education, 24 (6), 881-896.

Warnaby G., Bennison, D., Davies, B.J. (2005), "Marketing communications in planned shopping centres: evidence from the UK", International Journal of Retail \& Distribution Management, 33, 11/12, pp.893.

Warrinton, N.H. (2001). Shopping centre development strategies for emerging markets in Kwazulu-Natal. PhD. Thesis. Pretoria. University of South Africa.

Wee, K.N.L and Tong, K.W. (2005). The 4 Rs of Asian Shopping Centre Management, Singapore: Marshall Cavendish Academic.

Wilson, J. (2010). Essentials of Business Research. A guide to doing your research project. Great Britain: Sage Publications.

Zahra, S. A., Filatotchev, I., and Wright, M. (2009). How do threshold firms sustain corporate entrepreneurship? The role of boards and absorptive capacity. Journal of Business Venturing, 24(3): 248-260.

Zakim, E. (2000). Labour relations concepts. $4^{\text {th }}$ Edition. New York: Pearson Education.

Zheng, T. (2010). Linking organizational culture, structure, strategy, and organizational effectiveness: Mediating role of knowledge management. Journal of Business Research, 63(7):763-771.

University of Technology, Teaching and Learning Model. (2012). Which can be accessed from: www.vut.ac.za.www.out.ac.za

Zikmund, W.G., Babin, B.J., Carr, J.C. \& Griffin, M. (2010). Business Research methods. 8th ed. Canada: South Western Cengage Learning. 